\title{
Transmission of some species of internal parasites in horse foals born in 2013 in the same pasture on a farm in Central Kentucky
}

\author{
S. C. TOLLIVER, E. T. LYONS*, M. K. NIELSEN, J. L. BELLAW
}

\begin{abstract}
Department of Veterinary Science, University of Kentucky, Gluck Equine Research Center, Lexington, Kentucky 40546-0099
*Email: elyons1@uky.edu
\end{abstract}

\section{Article info}

Received November 1, 2014 Accepted January 15, 2015

\begin{abstract}
Summary
The present research is a continuation of studies conducted periodically over 40 years on transmission of natural infections of internal parasites in the same horse herd on pasture (Field 10) on a farm in Central Kentucky. It included 12 mixed light horse foals born in 2013 and euthanatized between July, 2013 and April, 2014 for collection of internal parasites. Parasites found: Gasterophilus intestinalis, Strongyloides westeri, Parascaris equorum, Anoplocephala perfoliata, small strongyles (cyathostomes), Strongylus vulgaris, Strongylus edentatus and Thelazia lacrymalis. Prevalence generally was related to age of the foals. Overall prevalence and number of specimens were lower than in earlier studies except for $P$. equorum. There were 15 species (much fewer than previously) of small strongyles found and recorded by location in the large intestines. All stages of small strongyles encysted in the mucosa of the large intestine were recovered by artificial digestion and in significantly lower numbers in older foals.

Keywords: Strongylus spp. cyathostomes; Parascaris equorum; Strongyloides westeri; Anoplocephala perfoliata. Gasterophilus intestinalis; Thelazia lacrymalis
\end{abstract}

\section{Introduction}

Knowledge and understanding about transmission of internal parasites of horses are important for determining the best control measures for these organisms. This information is valuable not only locally because prevalence and life cycles for the various parasite species in horses are similar worldwide (Herd 1986; Matthews 2011). Differences can occur relative to transmission because of, for example, variable weather patterns, diet, stocking rate, and other factors such as genetic make-up of the parasites (Bucknell et al., 1995; Kuzmina et al., 2006). Multiyear parasite studies in horses are difficult because circumstances typically are not available for researchers to keep infected animals on the same pasture for long periods. There has been unique opportunity to do periodic studies on natural parasite infections in a horse herd that was first assembled and kept on the same pasture (Field 10) on a farm in Central Kentucky over 50 years ago (Lyons et al., 1990). This allowed "trailing" the parasites over the long period of studies to observe any changes in infection pattern. None of the horses, except an occasional replacement stallion, has been treated with a parasiticide since 1979. Transmission studies have been done sporadically depending upon the number of foals born per year. Ideally eight or more foals born in a year allow especially meaningful monthly necropsies to be done to follow transmission of the parasites by age of the foal and season of necropsy. The first multiyear parasite study in this herd was over a 19-year period (1971 -1989) (Lyons et al., 1990). Three later, and the last, publications on this subject were for the next seven-year period $(1989$ - 1995) (Lyons et al., 1991, 1994, 1997). It should be mentioned that the main reason for the long time period between the last and current research on parasite transmission in Field 10 was lack of "sufficient" foals for the study. This was because: 1) the old stallion, now replaced by a younger stallion, did not breed many mares for several years 2) old nonbreeding mares were not replaced with younger ones until a few years ago 3 ) some foals were used for other studies, and 4) the filly foals were saved for breeding. All information from the present research is compared to that of the earlier studies in Field 10 horses 


\section{Material and Methods}

Horse foals ( $n=12 ; 9$ colts and 3 fillies) born on the same pasture (Field No. 10) on a farm in Central Kentucky in 2013 were euthanatized for parasite studies. Diet consisted of grass hay which was either timothy or orchard grass and pasture containing clover, blue grass and various species of weeds. Supplemental feed given twice a day included whole oats and pellets consisting of oats, alfalfa meal, corn, molasses, soy bean products, plain salt, $\mathrm{CaCo3}$, vitamin $\mathrm{A}$ and $\mathrm{E}$ and selenium. Salt and mineral blocks were available ad lib. The foals were kept in Field 10 with their dams until necropsy. Usually the oldest foal (two in November and in July) was necropsied each month of the study beginning in July, 2013 and ending in April, 2014 when the last one was processed. Two exceptions to the schedule by age were for two foals necropsied earlier than planned: $13-C-41$ because its mother died and $13-\mathrm{C}-40$ because it had an incurable lung problem not related to parasitism). Specific data for the foals relative to sex and date of birth and necropsy including age are in Table 1. The sire and dams were mixed light horse and breeding was natural on pasture. None of the foals in the study was ever treated with a parasiticide.
A minimum of 100 small strongyle specimens were identified per sample of gut contents. However when only a few specimens were recovered, they were all identified and when numerous specimens were present, a minimum of $10 \%$ were identified. Retrieval of encysted small strongyle larvae from the mucosa/submucosa of the large intestine was by a digestion technique (Eysker et al., 1984). Mucosal strips were excised from each of the three large intestinal compartments; cecum, ventral colon, and dorsal colon, and trimmed to represent $5 \%$ of the organ weight. Digestion solution was prepared by adding $10 \mathrm{~g}$ of pepsin and $15 \mathrm{~mL}$ of concentrated hydrochloric acid to $1 \mathrm{~L}$ of warm tap water. Mucosae were scraped off the strips with glass slides and digested for three hours in about $200 \mathrm{~mL}$ of the digestion solution in a shaking incubator set at $37^{\circ} \mathrm{C}$. Following this, the volume of each suspension was increased to $1000 \mathrm{~mL}$ by adding tap water, and $4 \%$ aliquots were examined for the presence of early third stage (EL3), late third stage (LL3), and fourth stage (L4) larvae. Each larval count was multiplied by 500 to reach the number of larvae per intestinal compartment.

Small strongyles from the lumen of the large intestine of seven of the foals were counted. Identification of species of small strongyles was done according to characteristics published in the monograph

Table 1. General data on Field 10 horses(born in 2013) and nematode eggs(EPGs) and larvae (LPGS)/gram of feces

\begin{tabular}{|c|c|c|c|c|c|c|c|c|c|}
\hline \multirow{3}{*}{$\begin{array}{l}\text { Horse } \\
\text { I.D. No. }\end{array}$} & & & & \multicolumn{3}{|c|}{ Nematode EPGs } & \multicolumn{3}{|c|}{ Nematode LPGs } \\
\hline & \multicolumn{3}{|c|}{ Date } & & & & & & \\
\hline & Sex & Birth & $\begin{array}{c}\text { Killed } \\
\text { (age-days) }\end{array}$ & P.equorum & Strongyle & S.westeri & S.v. & Cyath & S.westeri \\
\hline $13-\mathrm{C}-41$ & male & $5-16-13$ & $7-8-13(53)$ & 0 & 0 & POS. & & ND & \\
\hline $13-30$ & male & $2-12-13$ & $7-11-13(149)$ & 0 & 0 & ---- & & ND & \\
\hline $13-40$ & male & $3-4-13$ & $8-20-13(169)$ & 600 & 730 & POS. & --- & 120 & POS \\
\hline $13-51$ & female & $3-24-13$ & $9-23-13(183)$ & 0 & 560 & --- & --- & 40 & --- \\
\hline 13-C-39 & male & $4-17-13$ & $10-15-13(181)$ & 150 & 1310 & --- & --- & 270 & ---- \\
\hline $13-61$ & male & $4-2-13$ & $11-6-13(218)$ & 0 & 1460 & --- & ---- & 980 & --- \\
\hline $13-63$ & female & $4-2-13$ & $11-24-13(236)$ & & 1120 & --- & ---- & 300 & ---- \\
\hline $13-261$ & male & $4-25-13$ & $12-10-13(229)$ & 0 & 1730 & ---- & ---- & $\begin{array}{l}760 \\
\mathrm{ND}\end{array}$ & --- \\
\hline $13-50$ & male & $5-13-13$ & $1-4-14(236)$ & 0 & 870 & --- & & & \\
\hline $13-C-40$ & male & $9-2-13$ & $2-11-14(162)$ & & ND & & -- & 640 & POS \\
\hline $13-260$ & female & $5-28-13$ & $3-18-14(294)$ & 0 & 800 & --- & 90 & 330 & POS \\
\hline $13-65$ & male & $6-26-13$ & $4-15-14$ (293) & 0 & 1440 & ---- & ---- & 120 & ----- \\
\hline
\end{tabular}

P. equorum = Parascaris equorum; S. westeri = Strongyloides westeri; Cyath. = cyathostome/(Small strongyle); S.v. = Strongylus vulgaris; ND = no data; POS. = positive; ---- = negative

Horses in surrounding fields to Field 10 have been treated routinely ( 3 or 4 times per year) with ivermectin since 1990. Methods for necropsy and recovery of internal parasites of the foals and determining fecal egg counts (EPG) and larval counts (LPG) per gram of feces were as described previously (Drudge et al., 1963; Lyons \& Drudge, 1975; Lyons et al., 1976, 1981, 1983, 1994). For instance fecal egg counts were determined using a sucrose flotation method with a sensitivity of 10 eggs/gram of feces. Large intestinal lumen specimens of small strongyles were enumerated from aliquot samples of 1 to $2 \%$ of the entire contents. by Tolliver (2000; revised 2012) for five of these foals (13-40, 13$50,13-51,13-63,13-261)$. The term small strongyles in this paper is used from the historic taxonomy of inclusion of all species of strongyles except those in the genus Strongylus.

Statistical analysis of differences of various parasite counts between different age groups was done. Foals were divided into those necropsied before 200 days of age $(n=6)$ and those necropsied between 200 and 300 days of age $(n=6)$. Analysis for statistical differences between groups was performed with SAS software (version 9.3, SAS Institute). Mixed linear models were constructed 


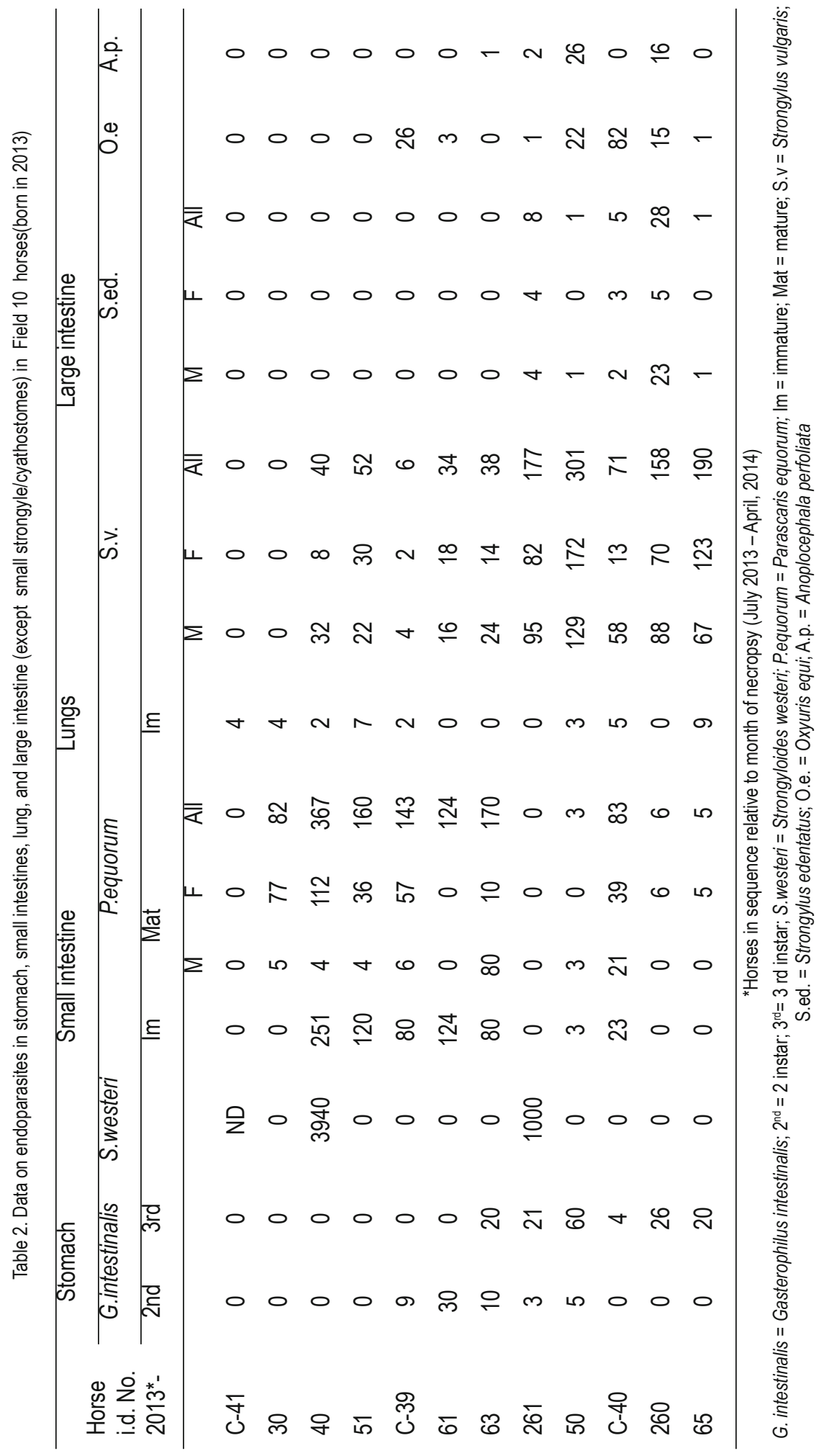


for analyzing the relationship between small strongyle mucosal larvae and the foal age categories defined above. The 'mixed procedure' was used with foal ID as random effect. Foal age category, gender, season of birth (February - April or May - September), and time of euthanasia (July - August, October - December, or January and onwards) were included as class variables, while all other variables were considered continuous. Each of the small strongyle larval categories (total mucosal burden, EL3, LL3, L4) as well as large strongyle larval categories $(L 4, L 5)$ were analyzed separately for both total counts and separated out on counts generated from the cecum, ventral colon, and dorsal colon. Interaction terms were evaluated between foal age category and time of euthanasia. Whenever any of these variables were found significant, a 'least square means' analysis was used for a Tukey's pairwise comparison of groups. Further, linear correlations were analyzed between foal age (in days) and parasite egg counts. Results were interpreted as significant at the $\alpha=0.05$ level.

\section{Results}

Data in the current study on the counts of the EPGs and LPGs are presented in Table 1. EPG values for ascarids were 150 - 600 for the two positive foals and for strongyles were 560 - 1440 for the nine positive foals; the two youngest foals were negative and there was no count done for one foal. Strongyle egg counts were significantly and positively correlated with age of the foals $(r=0.68, p=0.029)$, but not with luminal worm burdens. Strongyloides westeri eggs (not counted) were found in feces of only two foals. Counts of the LPGs (free-living third stage strongyle larvae-L3) for the nine foals whose feces was cultured were 40 980 for small strongyles and 90 for Strongylus vulgaris for the only positive foal. Strongyloides westeri L3 (not counted) were found in three foals.

Records on internal parasites (except cyathostomes/small strongyles) recovered from the stomach, small intestines and large intestines of foals are summarized (Table 2). Larvae of the bot fly Gasterophilis intestinalis were not found in the mouth (tongue/between teeth) of any foals. They were recovered from the stomach of foals as $2^{\text {nd }}$ instars in October through January $(n=3-30)$ and $3^{\text {rd }}$ instars in November through April $(n=4-60)$. No nematodes were recovered from the stomach of the foals. Strongyloides westeri specimens were found in the small intestines of only two foalsone in August and the other in December. Considering the two foals with specimens and two more positive in LPGs, that means only four were definitely infected with $S$. westeri.

Ascarid (Parascaris equorum) immature specimens ( 2 - 9/foal) were recovered from the lungs in all months except November and December. These parasites were detected in the small intestines as immatures ( $3-251 /$ foal) in August through February except November and December and matures ( $3-112 /$ foal) in July (at 149 days) through February except November and December. Combined numbers of immature and mature ascarids in the small intestines were highest in August ( $3-367 /$ foal). In general, both stages declined greatly by November when the foals grew older. Small strongyle species identified from the five foals are summarized according to location in the lumen of the three major com- partments of the large intestine i.e. cecum, ventral colon, and dorsal colon (Fig. 1). A total of 15 species was found. The number of species was 10 from the cecum and 12 each from the ventral colon and dorsal colon. Number of small strongyles recovered from the seven foals for which specimens were counted varied from 300 to 85,150 . In the present study, the mucosal digests for recovery of larval small strongyles revealed that the older foals generally had the lowest counts for each of the three identified stages. (Fig. 2). Strongylus vulgaris adults $(6-301 / \mathrm{foal})$ were found in the large intestines in August (at 169 days) through April (at 293 days). This species of nematode was found in the Cranial Mesenteric Arteries (CMA) and adjacent arteries from July (at 149 days) as fourth stage (L4) (14 - 126/foal) and fifth stage (L5) (11 - 144/ foal) through April (supplementary Table 1; Fig. 3). Combination of the number of both stages of migrating S. vulgaris is $25-270$ / foal. Pathological findings associated with $S$. vulgaris are summarized in supplementary Table 2 . There was a general pattern of S. vulgaris being prevalent as L4 and L5 in the CMA in higher numbers in earlier months and as adults in the large intestines in later months. Statistical analyses revealed no statistical differenc-

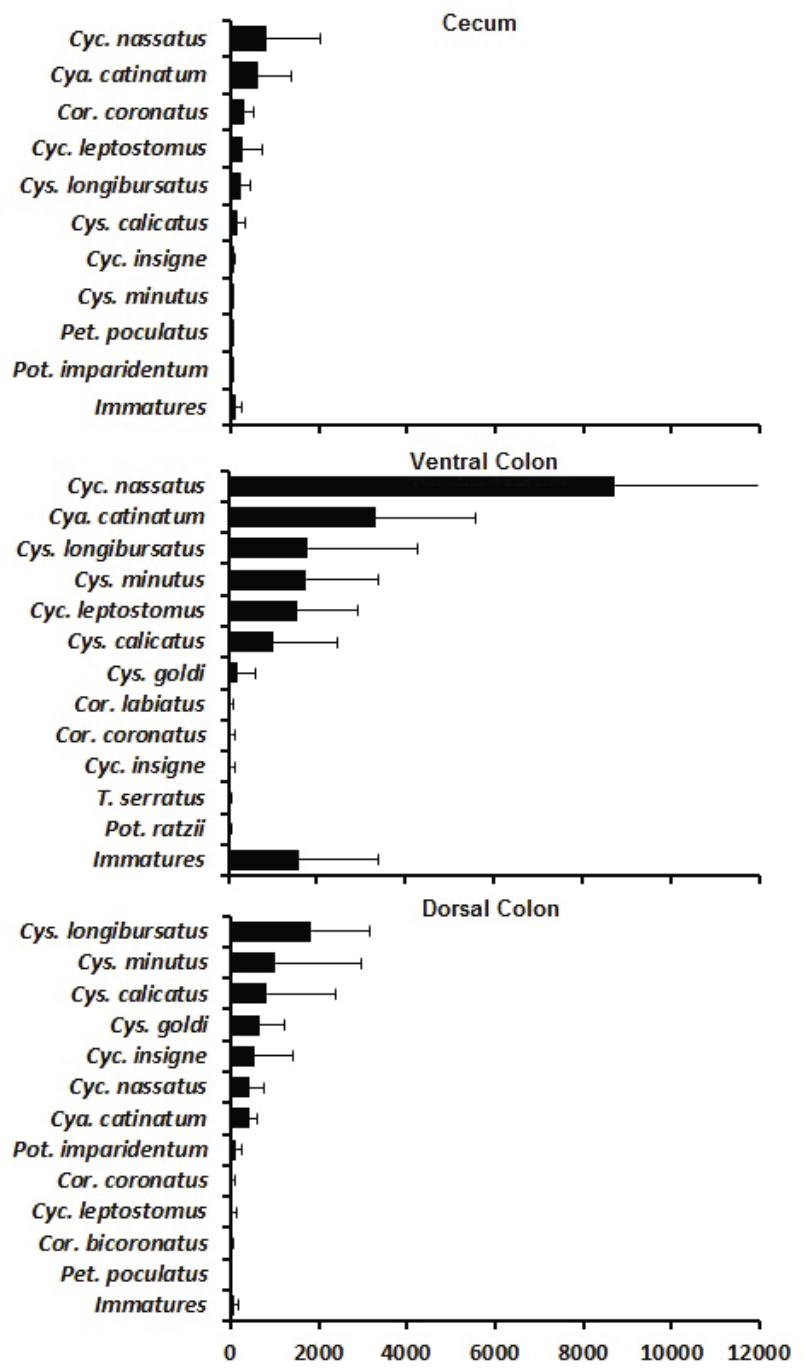

Fig. 1. Total counts of identified small strongyle species from five foals in each of the three large intestinal compartments; cecum, ventral colon, and dorsal colon. Error bars designate $95 \%$ confidence intervals 

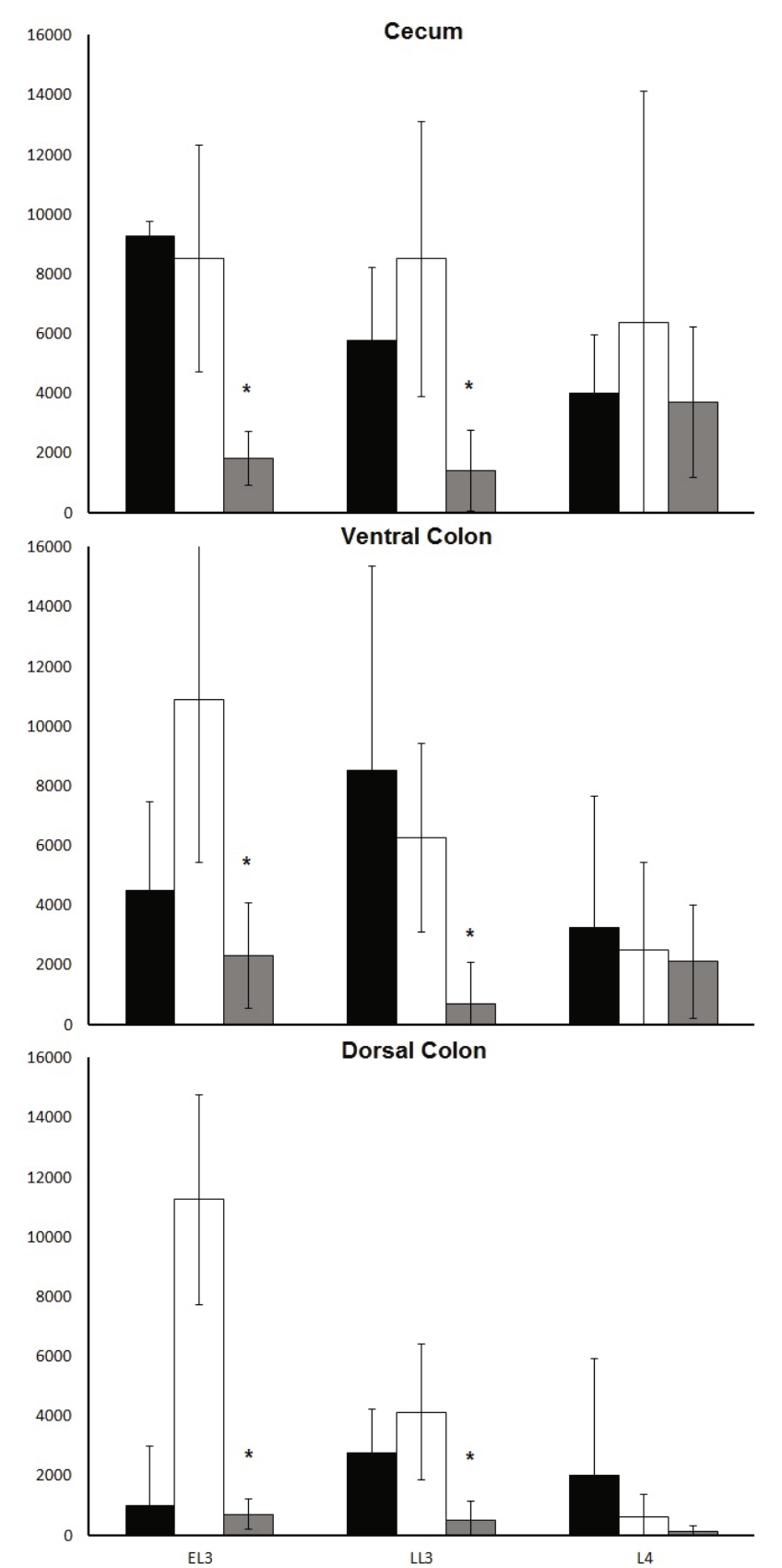

Fig. 2. Mean counts of early third stage (EL3), late third stage (LL3), and fourth stage small strongyle larvae (L4) in three age groups of foals; $<100$ days (black columns, $n=2$ ), $100-200$ days (white columns, $n=4$ ), and $>200$ days (grey

columns, $n=6$ ). Error bars designate $95 \%$ confidence intervals.

Asterisks ( $\left.{ }^{*}\right)$ indicate statistical differences between foals older than and younger than 200 days of age

es in larval counts between age groups for any of the larval stages encountered (Fig. 3). In general, pronounced pathological findings were noted in all of the CMAs, with some variation between foals (supplementary Table 2).

Strongylus edentatus were found in the large intestines in December through April in small numbers $(1-28 / f o a l)$. These parasites were found in the Ventral Abdominal Wall (VAW) and peritoneal cavity (supplementary Table 1) August (at 169 days) through April as $L 4(1-48 /$ foal) and $L 5(5-374)$. Combined numbers of $L 4$ and L5 S. edentatus in the VAW are $6-416 /$ foal.
The perfoliated tapeworms (Anoplocephala perfoliata) were found in November (at 236 days) to March except for February (Table 2). The highest number of tapeworms per foal was at seven months. Adult pinworms (Oxyuris equi) (1 - 82/foal) were found in the large intestines October (at 181 days) through April. The youngest infected foal (at 162 days) had the highest number of specimens. Eyeworms (Thelazia lacrymalis) were found as early L5 (1 - 2/foal) in August (at 169 days), September and January - April (Table 2).

\section{Discussion}

Research in the present study in the 2013 foals is compared to that of the earlier studies (Lyons et al., 1990, 1991, 1994, and 1997.

There was a tremendous decline in numbers of $G$. intestinalis per foal in Field 10, compared to earlier studies, especially the 19-year period $(1971-1989)$. This no doubt is related to the ivermectin treatment of horses in surrounding pastures for over 20 years. Thus the potential additional source of these flying insects to deposit their eggs on hairs of horses in Field 10 has been reduced
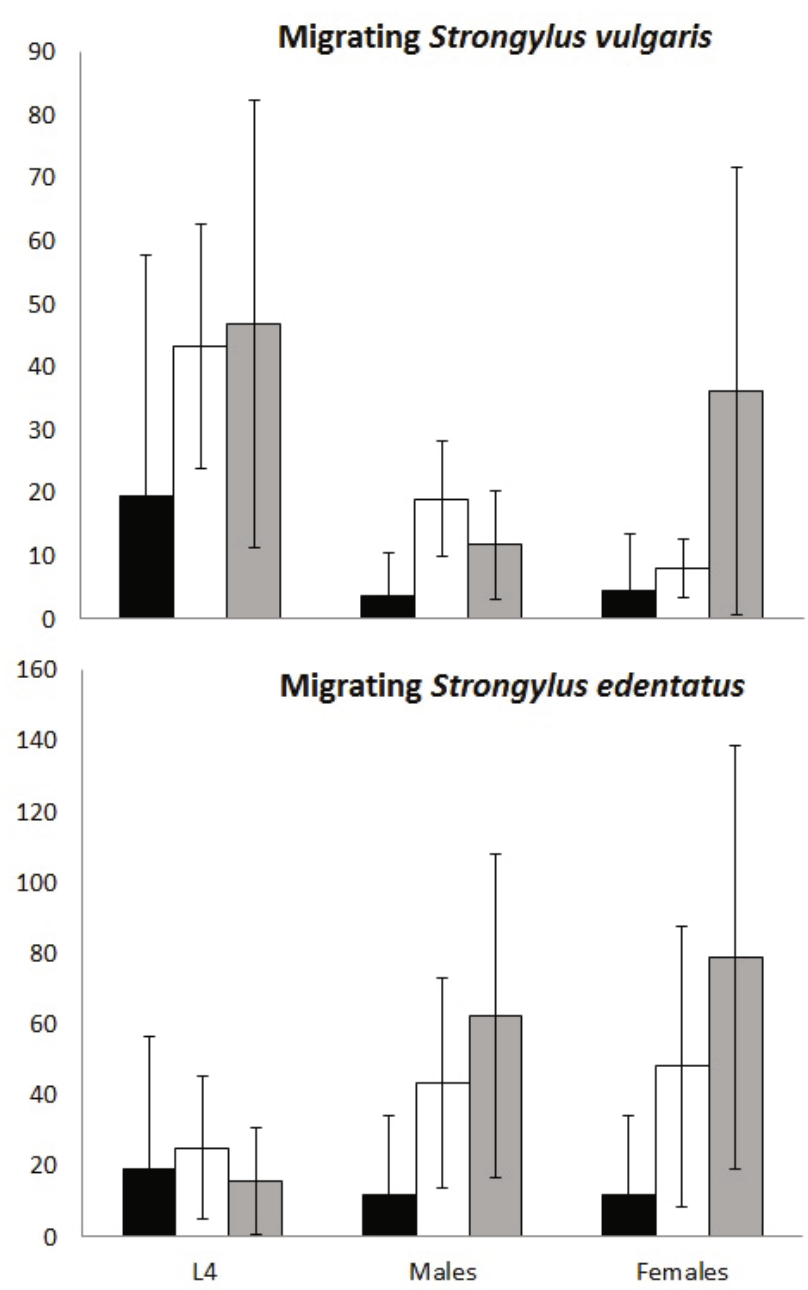

Fig. 3. Mean counts of fourth stage large strongyle larvae (L4) in three age groups of foals; $<100$ days (black columns, $n=2$ ), 100-200 days (white columns, $n=4$ ), and $>200$ days (grey columns, $n=6$ ). Error bars designate $95 \%$ confidence intervals. Data are shown for Strongylus vulgaris larvae in the Cranial Mesenteric Artery and adjacent branches, as well as $S$. edentatus in the ventral abdominal wall and perirenal fat tissue 
Supplementary Table 1. Data on endoparasites in cranial mesenteric artery, ventral abdominal wall and eyes of Field 10 horses (born in 2013)

\begin{tabular}{|c|c|c|c|c|c|c|c|c|c|c|c|}
\hline \multirow{3}{*}{$\begin{array}{l}\text { Horse } \\
\text { i.d.No } \\
\text { 2013.* }\end{array}$} & \multicolumn{4}{|c|}{ CMA } & \multicolumn{4}{|c|}{ VAW } & \multicolumn{3}{|c|}{ Eyes } \\
\hline & \multicolumn{4}{|c|}{ S.V. } & \multicolumn{4}{|c|}{ S.ed. } & \multicolumn{3}{|c|}{ T.lac. } \\
\hline & L4 & $\mathrm{M}$ & $F$ & All & L4 & $M$ & $F$ & All & $M$ & $F$ & All \\
\hline C-41 & 0 & 0 & 0 & 0 & 0 & 0 & 0 & 0 & & ND & \\
\hline 30 & 31 & 13 & 3 & 47 & 0 & 0 & 0 & 0 & 0 & 0 & 0 \\
\hline 40 & 60 & 15 & 12 & 87 & 48 & 67 & 90 & 205 & 0 & 1 & 1 \\
\hline 51 & 39 & 7 & 9 & 55 & 38 & 23 & 23 & 84 & 1 & 0 & 1 \\
\hline C-39 & 60 & 15 & 12 & 87 & 34 & 46 & 71 & 151 & 0 & 0 & 0 \\
\hline 61 & 73 & 28 & 35 & 136 & 38 & 38 & 50 & 126 & 0 & 0 & 0 \\
\hline 63 & 19 & 14 & 20 & 53 & 4 & 31 & 44 & 79 & 0 & 0 & 0 \\
\hline 261 & 22 & 2 & 10 & 34 & 1 & 1 & 4 & 6 & 0 & 0 & 0 \\
\hline 50 & 126 & 19 & 125 & 270 & 42 & 161 & 213 & 416 & 1 & 1 & 2 \\
\hline C- 40 & 22 & 33 & 5 & 60 & 18 & 61 & 31 & 110 & 0 & 0 & 0 \\
\hline 260 & 14 & 1 & 10 & 25 & 2 & 95 & 115 & 212 & 0 & 2 & 2 \\
\hline 65 & 27 & 6 & 17 & 50 & 7 & 49 & 48 & 104 & 0 & 1 & 1 \\
\hline
\end{tabular}

greatly because ivermectin is highly efficacious against species of Gasterophilus (Torbert et al., 1982).

Absence of stomach nematodes was similar to the last study (Lyons et al., 1997) where only a few foals were infected with Trichostrongylus axei and Habronema muscae and the numbers per foal were low. Prevalence of Strongyloides westeri in the small intestine was lower than found in previous studies in foals in Field 10. There may have been more foals positive but possibly numbers of these worms were too low in some cases to be detected in the recovery method. The numbers of ascarids have remained essentially similar throughout the 40-year study. The decrease of ascarids in foals as they aged is probably due to immunity (Russell 1948; Clayton 1978). In the present study, ascarids are designated as $P$. equorum. However in a recent publication, ascarids from this herd were karyotyped and identified as Parascaris univalens (Nielsen et al., 2014).

Overall the number of adult/immature small strongyles in the lumen of the large intestine was less in the present than past examined foals in Field 10. Different species of small strongyles typically prefer inhabiting certain areas (cecum, ventral colon, and dorsal colon) in the lumen of the large intestine (Ogbourne 1978). This was evident in the foals in the present study. Typically about $10 \%$ of the species prefer being in the cecum and the remainder are located equally in the ventral and dorsal colons (Ogbourne 1978). Arrested development of encysted stages of small strongyles and a resultant accumulation of these is a phenomenon which seems to increase with age (Chapman et al., 2003). This suggests that continued exposure and the host immune response are key fac- tors in this process. Little is known about this dynamic in foals, and the data presented herein provide a useful insight. The fact that the older foals had significantly fewer mucosal strongyle larvae, can be explained by these animals being necropsied mostly in the autumn and winter months, when the strongyle infection pressure can be considered much lower compared to earlier in the season. One conclusion from this study was that in the absence of a mucosal arrest as observed in older horses, mucosal larval counts merely reflect the infection pressure.

The general pattern of $S$. vulgaris being prevalent as $L 4$ and $L 5$ in the CMA in higher numbers in earlier months and as adults in the large intestines in later months is similar to that in the last study (Lyons et al., 1997). However in that earlier study, there were much larger numbers of specimens present in both of those anatomic sites.

The few foals infected with adult $S$. edentatus and the low numbers present were not unexpected because of the long (about 11 months) prepatent period; most of the foals were less than this age like foals in the last study (Lyons et al 1997). The "early-arrived" specimens in the large intestine of the first infected foal at 229 days of age probably were not patent yet; this was supported by lack of larvae in coproculture. The numbers of specimens in the VAW were similar to those reported in the last study (Lyons et al., 1997).

The highest number of $A$. perfoliata in foals at seven months of age was similar to that found previously in foals in this field. Prevalence of O.equi was higher than found in earlier studies in foals in Field 10. 


\begin{tabular}{|c|c|c|c|c|c|}
\hline Foal & $\begin{array}{c}\text { Fibrinous } \\
\text { tracts }\end{array}$ & Celiac artery & $\begin{array}{c}\mathrm{CMA}, \\
\text { main lesion }\end{array}$ & CMA, minor & Tota \\
\hline $13 / 61$ & 2 & 1 & 4 & 2 & 9 \\
\hline $13 / 65$ & 4 & 1 & 4 & 1 & 10 \\
\hline $13 / 260$ & 3 & 2 & 4 & 0 & 9 \\
\hline $13 / C 40$ & 4 & 2 & 4 & 1 & 11 \\
\hline $13 / 50$ & 4 & 2 & 4 & 2 & 12 \\
\hline $13 / 261$ & 2 & 1 & 4 & 3 & 10 \\
\hline 13/C39 & 4 & 0 & 4 & 2 & 10 \\
\hline $13 / 51$ & 4 & 0 & 4 & 1 & 9 \\
\hline $13 / 40$ & 4 & 1 & 4 & 1 & 10 \\
\hline $13 / 63$ & 3 & 1 & 4 & 1 & 9 \\
\hline
\end{tabular}

Fibrinous tracts: $0=$ no tracts, $1=$ less than 3 visible, $2=$ moderate amount of tracts, but some clear areas, $3=$ numerous tracts, $4=$ extensive tracts throughout the abdominal aorta

Celiac Artery: $0=$ no lesions, $1=$ small pocket with some reaction, $2=$ small pocket with active inflammation and larvae present

CMA, main: $0=$ no lesions, $1=$ small pocket with some reaction, $2=$ small pocket with active inflammation and larvae present, $3=$ medium-sized aneurysm $(3-8 \mathrm{~cm}$ long) with larvae and chronic-active inflammation, $4=$ Large aneurysm $(>8 \mathrm{~cm})$ with larvae and chronic-active inflammation

CMA, minor: $0=$ no lesions, $1=$ small pocket with some reaction, $2=$ small pocket with active inflammation and larvae present, $3=$ more than one small pocket with active inflammation and larvae present

The prevalence and number of $T$. lacrymalis per foal were much lower than in the last study. Possibly there were less face flies (Musca autumnalis), the intermediate host (Lyons \& Drudge 1975), to infect the 2013 foals because dairy cattle are no longer located near the foals like in previous studies. Although cattle typically are not infected with T.lacrymalis, they are a favorite host for feeding of adult face flies and cattle feces are ideal for fly development. Explanation of why there was a decline of Strongyloides westeri, small strongyles and Strongylus vulgaris since the last study on parasites of the Field 10 herd is not apparent. The question arises whether the improved diet since the last study, by feeding supplemented grain twice a day, possibly increased the ability of the foals to diminish infection with these parasites. It has been reported that increased nutrition in ruminants such as sheep, resulted in lowered nematode numbers, which was possibly due to enhancement of the immune system (Coop \& Holmes, 1996). The present authors, in literature review on this issue with horse parasites, found that published research is lacking. One study in lactating saddle horse mares revealed no apparent difference in parasite (cyathostome) infection in those with increased vs. nonincreased nutrition (Collas et al., 2014). Climatic conditions can affect the hatching/survival of nematode eggs/larvae. Some of these data are available for the current study (personal communication-University of Kentucky Agricultural Weather Center). During January 2013 through April, 2014 when the last foal was necropsied, precipitation was +0.21 to +15.95 inches departure from normal. From the dates (July, 2013 to April, 2014) the first foal to the last foal necropsied, precipitation measured +9.37 to +15.97 inches above normal. Air temperature during the same time periods was essentially normal.
Thus the amount of rain was usually high which should have been quite favorable for development of parasitic stages on pasture. If so that would not explain the decline of prevalence of several parasite species in the foals.

The research presented here demonstrated the advantage of long-term research on parasites in the same horse herd without intervention of chemotherapy except for occasional treatment of a replacement stallion. This situation allowed comparison of parasite transmission and burden under similar environmental conditions over the noteworthy extensive period of over 40 years.

Overall, compared to the last studies, there was a decline in prevalence/intensity of bots, strongyloides, S.vulgaris, cyathostomes, and eyeworms but not of ascarids, tapeworms and pinworms. The reason for the decrease of bots and eyeworms is evident but it is not for the other parasites reduced in occurrence.

\section{Conflict of interest statement}

The authors declare no potential conflicts of interest with respect to the research, authorship, and/or publication of this article.

\section{Acknowledgement}

This investigation (paper no.14-14-095) made in connection with a project of the University of Kentucky Agricultural Experiment Station and is published with the approval of the director. Research in the animals used in the study was approved by the University of University of Kentucky Institutional Animal Care and Use Committee (IACUC) under Protocol 2008-0257. 


\section{References}

BuCKNelL, D.G., GASSER, R.K., BeVERIDGE, I. (1995): The prevalence and epidemiology of gastrointestinal parasites of horses in Victoria, Australia. Int. J. Parasitol., 25: 711 - 724. DOI: 10.1016/00207519(94)00214-9

Chapman, M.R., French, D.D., Klel, T.R. (2003): Prevalence of strongyle nematodes in naturally infected ponies of different ages and during different seasons of the year in Louisiana.J.Parasitol., 89: 309 - 314. DOI: 10.1645/0022-3395 (2003)089[0309: POS$\mathrm{NIN]} 2.0 . \mathrm{CO} ; 2$

CLAYTON, H.M. (1978): Ascariasis in foals. Vet. Rec.,102: 553 556. DOI: $10.1136 / v r .102 .25 .553$

Collas, C., Fleurance, G., Cabaret, J., Martin-Rosse, W., Wimel, L., Cortet, J., Dumont, B. (2014): How does the suppression of energy supplementation affect herbage intake, performance and parasitism in lactating saddle mares? Animal., 8(8): 1290 - 1297. DOI: $10.1017 / S 175173111400127 X$

Coop, R.L., Holmes, P.H. (1996): Nutrition and parasite interaction. Int. J. Parasitol., 26: 951 - 962. DOI: 10.1016/S00207519(96)80070-1

Drudge, J.H., Szanto, J., Wyant, Z.N., Elam, G.W. (1963): Critical tests of thiabendazole as an anthelmintic in the horse. Am. J. Vet. Res., 24: 1217 - 1222

Eysker, M., Jansen, J., Mirck, M.H. (1984): Inhibited development of cyathostominae in the horse in the early 3 rd stage. Res. Vet. Sci., 37: $355-356$

HERD, R.P. (1986): Epidemiology and control of parasites in northern temperate regions. Vet. Clin. North Am. Equine Pract., 2: 337 $-355$

Kuzmina, T.A., Kuzmin, Y.I., Kharchenko, V.A. (2006): Field study on the survival, migration and overwintering of infective larvae of horse strongyles on pasture in central Ukraine. Vet. Parasitol., 141: 264 - 272. DOI: 10.1016/j.vetpar.2006.06.005

LYoNs, E.T., DRUDGE, J.H. (1975): Occurrence of the eyeworm Thelazia lacrymalis in horses in Kentucky. J. Parasitol., 61: 1122 1124. DOI: $10.2307 / 3279396$

Lyons, E.T., DrudGe, J.H., Toluiver, S.C. (1990): Prevalence of some internal parasites found (1971-1989) in horses born on a farm in central Kentucky. J. Equine Vet. Sci., 10: 99-107. DOl: 10.1016/S0737-0806(06)80114-0

LYons, E.T., DRUDGe, J.H., Tolliver, S.C. (1976): Thelazia lacrymalis in horses in Kentucky and observations on the face fly (Musca autumnalis) as a probable intermediate host. J. Parasitol., 62: 877 - 880. DOI: $10.2307 / 3279177$

Lyons, E.T., Drudge, J.H., Swerczek, T.W., Crowe, M.W., TollivER, S.C. (1981): Prevalence of Strongylus vulgaris and Parascaris equorum in Kentucky Thoroughbreds at necropsy. J. Am. Vet. Med. Assoc., 179: 818 - 819

Lyons, E.T., Tolliver, S.C., Drudge, J.H. Swerczek, T.W., Crowe, M.W. (1983): Parasites in Kentucky Thoroughbreds at necropsy: Emphasis on stomach worms and tapeworms. Am. J. Vet. Res., 44: $839-844$

Lyons, E.T., Toliver, S.C., Drudge, J.H., Granstrom, D.E. Stamper, S., ColıINS, S.S. (1991): Transmission of some internal parasites in horses born in 1989 on a farm in central Kentucky. J. Helminthol. Soc. Wash., 58: $213-219$

Lyons, E.T., Tolliver, S.C. Stamper, S., Drudge, J.H., Granstrom, D.E. CoLLINS, S.S. (1994): Transmission of some species of internal parasites in horses born in 1990, 1991, and 1992 in the same pasture on a farm in central Kentucky. Vet. Parasitol., 52: 257 269. DOI: 10.1016/0304-4017(94)90117-1

Lyons, E.T., Toluiver, S.C., Collins, S.S., Drudge, J.H., Granstrom, D.E. (1997): Transmission of some species of the same pasture on a farm in central Kentucky. Vet. Parasitol., 70: 225 - 240. DOl: 10.1016/0304-4017(94)90117-1

MatThEws, J.B. (2011): Facing the threat of equine parasitic disease. Equine Vet. J., 43: 126 - 132 DOI: 10.1111/j.2042306.2010.00356.x

Nielsen, M.K., Wang, J., Davis, R., Bellaw, J.L., Lyons, E.T., Lear, T.L., GodAY, C. (2014): Parascaris univalens - a victim of largescale misidentification? Parasitol. Res., 113: 4485 - 4490. DOl: 10.1007/s00436-014-4135-y

OgbouRnE, C.P. (1978): Pathogenesis of cyathostome (Trichonema) infections of the horse. A review. Commonwealth Inst. Helminthol. Commonwealth Agric.Bureaux England. Misc. Pub., No 5, $25 \mathrm{pp}$.

RusseLL, A.F. (1948): The development of helminthiasis in Thoroughbred foals. J. Comp. Pathol.I, 58: 107 - 127.

TolLIVER, S.C. (2000; revised 2012): A Practical Method of Identification of North American Cyathostomes (Small Strongyles) in Equids in Kentucky. Univ. Ky. Ag. Exp. Sta. Bull., No. SR-2000-1, Monograph, $37 \mathrm{pp}$.

ToRBert, B.J., KRAmer, B.S., KLel, T.R. (1982): Efficacy of injectable and oral paste formulations of ivermectin against gastrointestinal parasites in ponies. Am. J. Vet. Res., 43: 1451 - 1453. 